\title{
BUDGET TRANSPARENCY INITIATIVE WEBSITE
}

\section{www.bti-ce.mod.bg}

$\mathrm{T}$

his site has been developed by a team of young computer specialists from the Ministry of Defence of the Republic of Bulgaria. It presents the Budget Transparency Initiative - part of the activity of Working Table III of the Stability Pact for South Eastern Europe - and provides complete information about it. The website gives a better understanding of the Initiative and all related activities. The information is structured in the following sections:

- Profile - provides description and structure of the bodies related to the BT Initiative such as the Multinational Steering Group, the Academic Working Group and the BTI Centre of Excellence;

- Meetings - informs about all meetings that have been held, starting from 2001;

- Papers - contain the full version of all the documents adopted during the sessions of the BTI bodies, including Progress Reports, and Annexes to these documents;

- Products - present the outcome of the Initiative, mainly the Yearbook on South-East European Defence Spending;

- Forthcoming events - informs about future activities and meetings;

- Points of contact - featuring the Secretariat of the BT Initiative.

The product has been developed with Dream Weaver 4.0. Internet Explorer is recommended for better viewing. If the site is browsed with Netscape Communicator, one might experience minor problems. This is a temporary inconvenience that will be eliminated in due course.

This is the first version of the site; it is subject to improvement. The site is being updated constantly. All new products related to the Initiative will be published on this site. The founders of the Initiative welcome all comments and proposals for improvement of the site, as well as the overall BTI activity. 